\title{
Adhesion between ethylene-propylene-diene monomer and thermoplastics in two-component injection molding: Effect of dicumylperoxide as curing agent
}

\author{
Brittany Laing ${ }^{1}$, Jozefien De Keyzer ${ }^{2}$, David Seveno ${ }^{3}$, Albert Van Bael ${ }^{1,3}$ \\ ${ }^{1}$ KU Leuven, Diepenbeek Campus, Materials Technology TC, Wetenschapspark 27, 3590 Diepenbeek, \\ Belgium
}

${ }^{2}$ KU Leuven, Diepenbeek Campus, Sustainable Chemical Process Technology TC, Wetenschapspark 27, 3590 Diepenbeek, Belgium

${ }^{3} \mathrm{KU}$ Leuven, Department of Materials Engineering (MTM), Kasteelpark Arenberg 44, 3001 Leuven, Belgium

Correspondence to: Brittany Laing - SB PhD Fellow at FWO (E-mail: $\underline{\text { brittany.laing@kuleuven.be) }}$

"This is the pre-peer reviewed version of the following article: Laing B, De Keyzer J, Seveno D, Van Bael A. Adhesion between ethylene-propylene-diene monomer and thermoplastics in two-component injection molding: Effect of dicumylperoxide as curing agent. J Appl Polym Sci. 2020;e49233, which has been published in final form at https://doi. org/10.1002/app.49233. This article may be used for noncommercial purposes in accordance with Wiley Terms and Conditions for Use of Self-Archived Versions."

\begin{abstract}
Dicumylperoxide (DCP) as curing agent in ethylene-propylene-diene monomer (EPDM) could induce chemical bonding and/or stimulate interdiffusion at the interface with thermoplastics in two-component (2K) injection molding. Therefore, EPDM mixtures containing DCP concentrations between 2 to 8 parts per hundred rubber (phr) were adhered to polar and non-polar thermoplastics. Changes in EPDM physico-mechanical bulk properties were analyzed, and the adhesion was evaluated by high temperature contact angle measurements and tensile testing. Results showed that DCP concentration did not influence EPDM-thermoplastic compatibility. However, EPDM adhesion with polyethylene (PE) did improve up to $6 \mathrm{phr}$ DCP (57\% adhesion) as crosslinking is promoted, while with polypropylene (PP) adhesion linearly decreased (from $55 \%$ to $35 \%$ adhesion) with higher concentrations due to prevailing scission reactions. Adhesion through chemical bonding with acrylonitrile-butadiene-styrene (ABS) caused better adhesion at $4 \mathrm{phr}$ (43\% adhesion) compared to polycarbonate (PC) at $4 \mathrm{phr}(13 \%$ adhesion) where only limited interdiffusion occurs. Furthermore, at these optimal DCP concentrations physico-mechanical properties require consideration as these properties were significantly affected.

\section{INTRODUCTION}

Ethylene-propylene-diene rubber as soft component in two-component injection molding offers excellent dynamic and heat aging properties together with resistance to polar solvents. Consequently, it is an ideal rubber for sealing applications. These seals are often incorporated and fitted mechanically or with an adhesive onto thermoplastics parts. However, a $2 \mathrm{~K}$ process combining EPDM with
\end{abstract}


thermoplastics would improve product reliability and offers perspectives for reducing material cost due to a re-design. ${ }^{1}$ Unfortunately, $2 \mathrm{~K}$ injection molding of EPDM combined with common thermoplastics like $P E, P P, A B S$ and $P C$ requires dealing with the low processing temperatures of the thermoplastic. Therefore, Bex et $\mathrm{al}^{1-3}$ developed a mold with thermally separated heat cavities and optimized the process to induce a thermoset rubber-thermoplastic adhesion. Additionally, Laing et al. ${ }^{4}$ showed the importance of investigating the influence of EPDM composition on the adhesion with polar and nonpolar thermoplastics. In that study, it was found that co-agent type and concentration at a fixed peroxide concentration significantly affect the adhesion strength and mechanism. To extend the scope of investigation, a study focusing on varying the peroxide concentration at a fixed co-agent concentration was deemed necessary and is presented here.

Organic peroxides, like DCP, are widely used curing agents that can cure both saturated and unsaturated polymers. ${ }^{5,6}$ Other advantages that peroxides offer are the improved thermal resistance and lower compression set, ideal for sealing applications. ${ }^{7}$ When exposed to heat, these peroxides will undergo homolytic cleavage by breaking the oxygen-oxygen bond yielding two radicals. These radicals can then initiate a hydrogen abstraction from the polymer chain, or an addition can take place to the double bond of unsaturated polymers creating a polymer radical. Finally, two radicals will recombine to form a carbon-carbon crosslink. ${ }^{5,6}$ Several studies have shown a significant influence of peroxide vulcanization on the crosslink density and general properties of vulcanized rubbers. ${ }^{8-10}$ Consequently, an influence of the peroxide curing agent on the adhesion at the interface can be expected as well. Furthermore, peroxides could induce a co-vulcanization reaction, or crosslinks, between EPDM and thermoplastics as unsaturations are not required. It may, however, be important that enough peroxides are present at the interface to implement this chemical bonding reaction. ${ }^{11}$ Therefore, it could be presumed that higher peroxide concentrations may lead to a better adhesion. Furthermore, Thust ${ }^{11}$ also indicated the occurrence of both interdiffusion and chemical bonding at a peroxide cured hydrogenated nitrile rubber-polyamide 6.6 (HNBR-PA 6.6) interface. This combination of adhesion mechanisms was also presumed in a previous study by the authors. ${ }^{4}$ For $\mathrm{PE}$, it is known that dicumylperoxide has a good efficiency to cure PE as the alkoxy radicals from DCP are prone to abstract hydrogen from $\mathrm{PE}$ and the extend of crosslinking is dependent on the peroxide amount. ${ }^{12-14}$ For PP, it is important to use a coagent assisted peroxide curing system to minimize degradation as chain scission competes with crosslinking. ${ }^{15,16}$. Studies of PP/EPDM thermoplastic vulcanizates (TPVs) have shown that DCP is less prone to degrade PP compared to other peroxides like di(2-tert butyl peroxy isopropyl)benzene or tertbutyl cumyl peroxide, but overall the peroxide concentration needs to be limited. ${ }^{7,17}$ Furthermore, peroxides can cure ABS which could lead to co-vulcanization with EPDM. ${ }^{6}$ Peroxides may also migrate to the surface at higher concentrations causing a change in compatibility with polar and non-polar thermoplastics. ${ }^{11}$ Overall, literature clearly shows the importance of peroxide concentration and its influence in blends, at interfaces and the general properties of polymers, but to the best of our knowledge an in-depth study on the effects on the EPDM-thermoplastic interface in $2 \mathrm{~K}$ injection molding for the proposed material combinations is still lacking.

In this study, the influence of peroxide curing agent in EPDM on the adhesion with polar and non-polar thermoplastics is investigated. Therefore, concentrations of DCP are varied while maintaining a fixed 
concentration of co-agent trimethylolpropane trimetacrylate (TMPT). The adhesion between EPDM and thermoplastics PE, PP, ABS and PC is evaluated by contact angle measurements at high temperature and tensile tests. Possible co-vulcanisation reactions and types of crosslinks between EPDM and the thermoplastics are discussed. Furthermore, cure characteristics and compound swelling are analyzed to determine the state of cure and crosslink densities as this may influence the adhesion mechanism. General properties of all EPDM compositions are determined as well, in particular tensile properties, thermal resistance, compressions set and hardness which are all important properties for sealing applications. Eventually, a final assessment is made of the optimal DCP concentration for each EPDMthermoplastic combination while taking into account the possible changes in rubber bulk properties.

\section{EXPERIMENTAL}

\section{Materials}

The rubber compounds, represented in Table 2, were mixed and provided by Hercorub, Belgium. The following raw materials were used: EPDM (Vistalon 2504N, Exxon Mobile, with Mooney Viscosity ML $1+4,125^{\circ} \mathrm{C}=25$ Mooney units (MU); ethylene content $=56.0 \mathrm{wt} \%$; ethylene norbornene (ENB) content $=$ $3.8 \mathrm{wt} \%)$; paraffinic oil (Sunpar 2280, Petronas); silane treated calcined kaolin filler (Polarite 103A, Imerys); zinc oxide and stearic acid. Trimethylpropane trimethacrylate (TMPT, 70\% active ingredient) was used as co-agent and concentrations between 2 and 8 phr of dicumylperoxide (DCP) with $40 \%$ active peroxide content were added. The chemical name and structure of components in the peroxide curing system components are listed in Table 1.

TABLE 1 Chemical names and structure of the peroxide curing system components.

\begin{tabular}{lll}
\hline Chemical name & Abbreviation & Chemical structure \\
\hline Dicumylperoxide & DCP & \\
$\begin{array}{l}\text { Trimethylolpropane } \\
\text { trimethacrylate }\end{array}$ & TMPT &
\end{tabular}

TABLE 2 EPDM compound compositions.

\begin{tabular}{lcccc}
\hline $\begin{array}{l}\text { Component } \\
\text { (phr) }\end{array}$ & DCP2 & DCP4 & DCP6 & DCP8 \\
\hline EPDM & 100 & 100 & 100 & 100 \\
Zinc oxide & 2.8 & 2.8 & 2.8 & 2.8
\end{tabular}




\begin{tabular}{lcccc}
\hline Stearic acid & 1 & 1 & 1 & 1 \\
Kaolin filler & 110 & 110 & 110 & 110 \\
Paraffinic oil & 30 & 30 & 30 & 30 \\
DCP $^{\mathrm{a}}$ & $2(7.4)^{\mathrm{b}}$ & $4(14.8)$ & $6(22.2)$ & $8(29.6)$ \\
TMPT $^{\mathrm{a}}$ & 2 & 2 & 2 & 2 \\
\hline
\end{tabular}

${ }^{a}$ Concentrations of DCP and TMPT are represented in phr of active amount.

${ }^{b}$ Values in parentheses correspond to milliequivalents of active DCP.

Each rubber compound was combined with two non-polar (a) and two polar (b) thermoplastics: (a) PP grade 400-GA05 (Ineos) (melting temperature $=164^{\circ} \mathrm{C}$, yield stress $=25 \mathrm{MPa}$ ), and high-density polyethylene (PE) grade M80064 (Sabic) (melting temperature $=135^{\circ} \mathrm{C}$, yield stress $=32 \mathrm{MPa}$ ); (b) $\mathrm{PC}$ grade Calibre 301-15 (Trinseo) (glass transition temperature $=150^{\circ} \mathrm{C}$, yield stress $=60 \mathrm{MPa}$ ), and $\mathrm{ABS}$ grade Novodur P2H-AT (Ineos) (glass transition temperature $=110^{\circ} \mathrm{C}$, yield stress $=44 \mathrm{MPa}$ ).

\section{EPDM-thermoplastic sample preparation}

Samples were made according to the process developed by Bex et al. ${ }^{1,3}$ on an Engel ES330H/80V/80HL-F equipped with a vertical rubber unit and a horizontal thermoplastic injection unit. To combine EPDM with thermoplastics a versatile mold was employed with a rubber and thermoplastic cavity. In this mold, first, all thermoplastics parts were produced separately in the thermoplastic cavity while a metal insert was placed in the rubber cavity. Afterwards, the metal insert was removed, a thermoplastic part was placed in the $2 \mathrm{~K}$ mold and overmolded with rubber, resulting in $2 \mathrm{~K}$ specimens with dimensions as shown in Figure 1 and a thickness of $2 \mathrm{~mm}$.

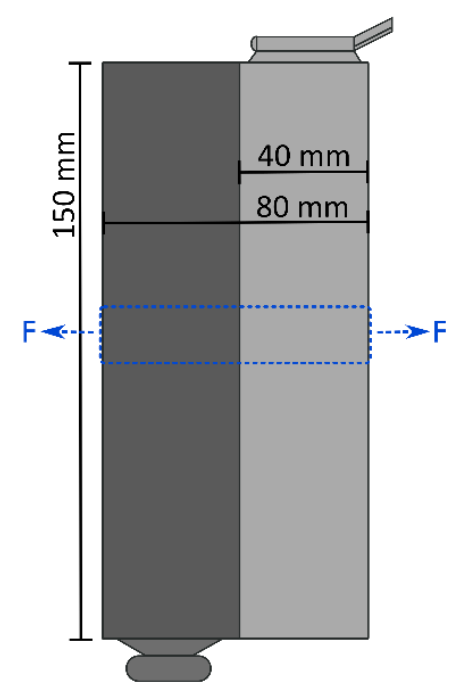

FIGURE $12 \mathrm{~K}$ specimen dimensions. The thickness of both the rubber and thermoplastic part is $2 \mathrm{~mm}$. The dotted line represents the sample location for tensile testing and how the force (F) will be applied to determine the adhesion strength. ${ }^{4}$ 
All injection molding parameters for the individual components are listed in Table 3. Recommendations by the suppliers were used for the injection and mold temperatures. The selected injection rate ensured constant viscosity and the high holding pressure caused a completely filled product without causing flash.

TABLE 3 Injection molding parameters.

\begin{tabular}{llllll}
\hline Injection molding parameters & PP & PE & PC & ABS & EPDM \\
\hline Injection temperature $\left({ }^{\circ} \mathrm{C}\right)$ & 230 & 230 & 300 & 260 & 80 \\
Mold temperature $\left({ }^{\circ} \mathrm{C}\right)$ & 20 & 20 & 80 & 70 & 180 \\
Injection rate $\left(\mathrm{cm}^{3} / \mathrm{s}\right)$ & 38 & 38 & 87 & 96 & 59 \\
Holding pressure $(\mathrm{bar})$ & 494 & 790 & 494 & 494 & 248 \\
\hline
\end{tabular}

During production of $2 \mathrm{~K}$ samples, the rubber cavity was set at $180^{\circ} \mathrm{C}$ to ensure vulcanization, while the thermoplastic cavity was set at a low temperature to achieve an optimal interface temperature for good adhesion as specified by Bex et al. ${ }^{1,2}$. Table 4 contains the mold temperatures of each cavity and the accompanying interface temperatures. These interface temperatures were experimentally determined by Bex et al. ${ }^{2}$ with an infrared camera (OPTRIS PI400). In addition, curing times are listed for all samples that ensured $90 \%$ vulcanization. These $90 \%$ vulcanization times were determined by the necessary times to vulcanize the rubber near the interface, as temperatures are much lower here than in the rubber bulk.

TABLE 4 Mold temperatures for thermoplastic and rubber cavity with the accompanying interface temperature and curing times.

\begin{tabular}{lcccc}
\hline & \multicolumn{4}{c}{ EPDM } \\
\cline { 2 - 5 } Mold temperature $\left({ }^{\circ} \mathrm{C}\right)$ & PP & PE & PC & ABS \\
\hline Thermoplastic cavity & 140 & 80 & 155 & 90 \\
Rubber cavity & 180 & 180 & 180 & 180 \\
Interface & 161 & 139 & 166 & 143 \\
\hline Curing time (s) & 1200 & 4000 & 800 & 4000 \\
\hline
\end{tabular}

\section{EPDM bulk properties}

\section{Cure characteristics}

Cure characteristics of each rubber compound, i.e. cure time $\left(t_{90}\right)$, scorch time $\left(t_{s_{2}}\right)$ and delta torque, ( $\Delta$ torque), were determined with a moving die rheometer (MDR2000E, Monsanto). As the temperature during injection molding in the rubber bulk is set at $180^{\circ} \mathrm{C}$, MDR measurements were taken at $180^{\circ} \mathrm{C}$ for $20 \mathrm{~min}$. However, due to the lower temperatures at the EPDM-thermoplastic interfaces (Table 4), rubber near the interface will have different cure characteristics. Therefore, vulcanization degrees at $160^{\circ} \mathrm{C}$ 
were measured during $45 \mathrm{~min}$ and at $140^{\circ} \mathrm{C}$ during $160 \mathrm{~min}$. Reversion resistance was determined for each compound at $180^{\circ} \mathrm{C}$ after 60 min according to eq.(1), as the curing times for EPDM-PE and EPDM$A B S$ were set at $4000 \mathrm{~s}$ to ensure vulcanization of the rubber near the interface leading to a long exposure to $180^{\circ} \mathrm{C}$ in the bulk.

Reversion index $(\%)=\frac{S^{\prime} \max -S_{R}^{\prime}}{S^{\prime} \max } \cdot 100$

$S_{\text {max }}^{\prime}$ and $S_{R}^{\prime}$ are respectively maximum torque and torque after $60 \mathrm{~min}$.

After injection molding, vulcanization degrees at the interface of all $2 \mathrm{~K}$ samples were checked by Shore A hardness measurements as hardness relates linearly to the vulcanization degree. ${ }^{18}$ Five hardness measurements were taken on each $2 \mathrm{~K}$ combination according to ISO 7619 with a measuring time of $15 \mathrm{~s}$ and interfacial vulcanization degrees were calculated according to eq.(2). ${ }^{2}$

Interfacial vulcanisation degree $=\frac{x-x_{\min }}{x_{\max }-x_{\min }}$

where $x$ is the hardness at a specific point $1 \mathrm{~mm}$ from, and parallel with the interface, $x_{\min }$ the hardness of unvulcanized rubber, and $x_{\max }$ the hardness of $100 \%$ vulcanized rubber.

\section{Crosslink density}

Crosslink density $v$ was determined by equilibrium swelling measurements in cyclohexane. Three test pieces of each vulcanized compound were swollen for $72 \mathrm{~h}$ according to ISO 1817 at $23^{\circ} \mathrm{C}$ in $70 \mathrm{ml}$ cyclohexane. Starting sample dimensions were $25 \mathrm{~m} \times 25 \mathrm{~mm} \times 2 \mathrm{~mm}$. After reaching equilibrium swelling, excessive solvent was removed with filter paper, samples were weighed $\left(m_{\max }\right)$, dried in an oven at $60^{\circ} \mathrm{C}$ for $24 \mathrm{~h}$ to remove all the solvent and finally reweighed $\left(\mathrm{m}_{0}\right)$. Volume fraction of rubber in the equilibrium swollen vulcanized sample $\left(\mathrm{V}_{\mathrm{r}}\right)$ was determined according to eq.(3), where $\rho_{s}$ and $\rho_{e}$ are the densities of solvent and elastomer samples. Density of the elastomer was determined with a METTLER Toledo density kit.

$V_{r}=\frac{m_{0} \rho_{s}}{m_{0}\left(\rho_{s}-\rho_{e}\right)+m_{\max } \rho_{e}}$

Crosslink density $v\left(\mathrm{~mol} / \mathrm{cm}^{3}\right)$ of each vulcanized compound was calculated according to eq. $(4)^{4}$ by applying the Flory-Rehner equation for tetrafunctional networks, where $V_{S}$ is the molar volume of cyclohexane $\left(108.105 \mathrm{~cm}^{3} / \mathrm{mol}\right)$ and $\chi$ is the Huggins polymer-solvent interaction parameter $(\chi=0.35$ for EPDM-cyclohexane ${ }^{19}$ ). An average crosslink density was taken of three samples and $95 \%$ confidence intervals are reported.

$v=-\frac{1}{2 V_{S}} \frac{\ln \left(1-V_{r}\right)+V_{r}+\chi V_{r}^{2}}{\left(V_{r}^{\frac{1}{3}}-0.5 V_{r}\right)}$

\section{Physico-mechanical properties}

Physico-mechanical properties were evaluated on the rubber vulcanized bulk part of EPDM-PP samples $\left(1200 \mathrm{~s}\right.$ vulcanization at $180^{\circ} \mathrm{C}$ ). Afterwards, samples were conditioned at $23^{\circ} \mathrm{C}$ for 3 days. Tests were 
selected based on important properties for the current material combinations, like good thermal resistance and mechanical strain, which are ideal for sealing applications. A Zwick Z050 equipped with a $1 \mathrm{kN}$ load cell was used at room temperature, a crosshead speed of $200 \mathrm{~mm} / \mathrm{min}$ and a gauge length of $13.5 \mathrm{~mm}$ to determine tensile properties. Shore A hardness was measured according to ISO 7619. Compression set tests were performed at $23^{\circ} \mathrm{C}$ for $24 \mathrm{~h}$ according to ISO 815 . Heat aging was evaluated by exposing vulcanized samples to $100^{\circ} \mathrm{C}$ in an air circulated oven for $72 \mathrm{~h}$ according to ISO 188 and reevaluating tensile strength and hardness. Significant differences between unaged and aged samples were compared by a paired t-test (for two dependent groups) with 0.050 as significance level. The null hypothesis corresponds to a zero mean difference between unaged and aged samples. When the $p$ value is smaller than 0.050 , the null hypothesis can be rejected, indicating a significant difference between unaged and aged samples. The statistical analyses for heat aging were executed on Minitab 17. Average values of three samples of all compounds and the accompanying $95 \%$ confidence intervals are reported.

\section{Adhesion Characterization}

\section{Compatibility measurements}

Similar to the previous study on the influence of co-agents on EPDM-thermoplastics adhesion ${ }^{4}$, contact angle measurements at high temperatures were executed to evaluate changes in material compatibility. Contact angles were assessed according to the method described by Bex et al. ${ }^{20}$. A Dataphysics OCA 15 plus, equipped with a Dataphysics TEC 350 temperature control unit was used and contact angles were calculated with Dataphysics SCA 202 analysis software.

Completely vulcanized rubber was selected as substrate to prevent further vulcanization during compatibility measurements. A comparison was made between EPDM substrates containing increasing concentrations of DCP (DCP2, DCP4, DCP6 and DCP8) to analyze the influence of DCP concentration on wetting between thermoplastics and EPDM. The surface composition of each substrate was checked by acquiring infrared (IR) spectra with a Perkin Elmer Spectrum 65 FTIR coupled to an attenuated total reflection (ATR) unit. The average roughness values $\left(R_{a}\right)$ of the rubber substrate, measured with a Diavite Compact VHF on the surface in the middle of the rubber part, were $0.47 \pm 0.09 \mu \mathrm{m}$ for DCP2, $0.45 \pm 0.17 \mu \mathrm{m}$ for DCP4, $0.49 \pm 0.20 \mu \mathrm{m}$ for DCP6 and $0.49 \pm 0.10 \mu \mathrm{m}$ for DCP8. These roughness values are low and comparable, limiting the effect of roughness on wetting, and therefore this is not taken into account. All samples were cleaned with isopropanol before measurements. A substrate with dimensions of $10 \times 10 \times 2 \mathrm{~mm}$ was placed in a heated chamber under nitrogen environment and stabilized for five minutes. Then, a thermoplastic granule was placed on the rubber substrate with the spherical side facing down. Chamber temperatures for $\mathrm{PE}, \mathrm{PP}$ and $\mathrm{PC}$ were respectively $180^{\circ} \mathrm{C}, 200^{\circ} \mathrm{C}$ and $230^{\circ} \mathrm{C}$ to enable the polymer to melt. ABS was not tested as degradation occurred too fast even under $\mathrm{N}_{2}-$ environment in the available heating chamber. After reaching a thermoplastic droplet with a contact angle of $110^{\circ}$, contact angles were registered every minute during $15 \mathrm{~min}$. Overall, the methodology was kept similar to the previous study by the authors ${ }^{4}$ to compare results as this is a follow-up study. Three measurements were performed for each combination of thermoplastic with EPDM rubber and average values with their $95 \%$ confidence intervals are reported. 


\section{Adhesion measurements}

EPDM-thermoplastic adhesion strength was evaluated by tensile testing. ${ }^{21-23}$ To be able to compare the adhesion strength to the bulk strength a similar method was used: tensile testing on a Zwick Z050 equipped with a $1 \mathrm{kN}$ load cell was used at room temperature with a speed of $200 \mathrm{~mm} / \mathrm{min}$ and a gauge length of $13.5 \mathrm{~mm}$. EPDM-thermoplastic samples were punched out the $2 \mathrm{~K}$ specimens (Figure 1) perpendicular to the interface in the middle of the sample, resulting in samples dimensions of $80 \times 10 x$ $2 \mathrm{~mm}$ for EPDM-PP and EPDM-PE. For EPDM-PC and EPDM-ABS samples, it was not possible with the available machine to punch out samples without damaging the interface due to the low adhesion and hardness of the thermoplastics. Thus, samples were cut out with a selected width of $30 \mathrm{~mm}$, as this still fitted between the clamps of the tensile machine, resulting in sample dimensions of $80 \times 30 \times 2 \mathrm{~mm}$. Adhesion strength $\left(\sigma_{a}\right)$ was also compared to the total strength of the rubber bulk $\left(\sigma_{t}\right)$ by calculating a percentage of adhesion according to eq.(5). Five adhesion measurements were performed for each material combination and $95 \%$ confidence intervals are reported.

Adhesion percentage $(\%)=\frac{\sigma_{a}}{\sigma_{t}} \cdot 100$

A post-fracture visual analysis was done of the thermoplastic interface surface with a Keyence VHX-500F digital microscope and a 50x magnification.

\section{RESULTS AND DISCUSSION}

\section{Effect of dicumylperoxide on EPDM bulk properties}

\section{Cure characteristics and crosslink density}

Cure characteristics of all EPDM compounds are listed in Table 5. As DCP concentration increases, a clear increase in $\Delta$ torque can be seen, which is also shown in Figure 2 . This is due to the improved crosslinking efficiency as peroxide decomposition follows first order reaction kinetics. ${ }^{24,}{ }^{25}$ Measurements of crosslink density (Figure 3) confirm $\Delta$ torque results indicating a linear correlation between crosslink density and DCP concentration. Furthermore, vulcanization times $\left(t_{90}\right)$ at $180^{\circ} \mathrm{C}$ and $160^{\circ} \mathrm{C}$ do not differ much between different concentrations. However, at $140^{\circ} \mathrm{C}$, higher concentrations do lead to better curing efficiency. Scorch time tends to decrease with higher concentrations at every temperature. Furthermore, due to the high curing times for EPDM-PE and EPDM-ABS (Table 3) to ensure vulcanization at the interface, reversion index was examined as the vulcanization temperature in the EPDM bulk is $180^{\circ} \mathrm{C}$ during this time. Reversion in all compounds remains limited and reduces with higher peroxide concentration. However, it is recommended to use higher concentrations for EPDM-PE and EPDM-ABS to minimize reversion in the EPDM bulk. Interfacial vulcanization degrees also show that curing times listed in Table 3 sufficed for all $2 \mathrm{~K}$ combinations as 90\% vulcanization degree was reached. 


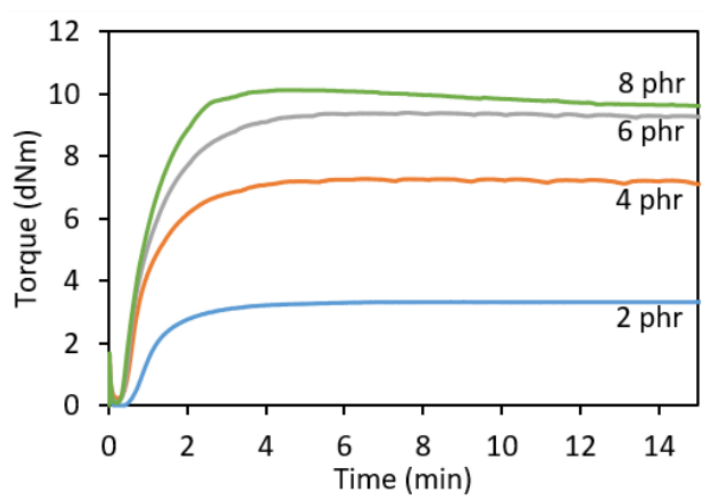

FIGURE 2 Torque-time curves for EPDM with varying DCP concentrations.

TABLE 5 Cure characteristics of the EPDM compounds.

\begin{tabular}{lcccc}
\hline \multicolumn{1}{c}{ Cure characteristics } & DCP2 & DCP4 & DCP6 & DCP8 \\
\hline$\Delta$ torque $180^{\circ} \mathrm{C}(\mathrm{dNm})$ & 3.34 & 7.05 & 9.29 & 10.06 \\
& & & & \\
$\mathrm{t}_{90}(\mathrm{~min})$ at $180^{\circ} \mathrm{C}$ & 2.65 & 2.49 & 2.65 & 2.14 \\
at $160^{\circ} \mathrm{C}$ & 17.96 & 16.79 & 18.47 & 17.07 \\
at $140^{\circ} \mathrm{C}$ & 118.38 & 117.16 & 106.45 & 102.46 \\
& 1.23 & 0.63 & 0.54 & 0.50 \\
$\mathrm{t}_{\mathrm{s} 2}(\mathrm{~min})$ at $180^{\circ} \mathrm{C}$ & 6.93 & 2.64 & 1.82 & 1.80 \\
$\quad$ at $160^{\circ} \mathrm{C}$ & 53.69 & 24.88 & 16.40 & 13.16 \\
$\quad 140^{\circ} \mathrm{C}$ & 14.39 & 15.34 & 10.18 & 1.38 \\
Reversion index $180^{\circ} \mathrm{C}$ & & & & \\
$60^{\prime}(\%)$ & $90 \pm 3$ & $96 \pm 2$ & $93 \pm 3$ & $95 \pm 1$ \\
\hline Interfacial vulcanization degree $(\%)$ & & & \\
\hline EPDM-PP & $98 \pm 2$ & $91 \pm 1$ & $93 \pm 1$ & $96 \pm 2$ \\
EPDM-PE & $90 \pm 1$ & $98 \pm 2$ & $100 \pm 3$ & $100 \pm 1$ \\
EPDM-ABS & $91 \pm 2$ & $99 \pm 2$ & $98 \pm 2$ & $99 \pm 1$ \\
\hline EPDM-PC & & & & \\
\hline
\end{tabular}

Swelling measurements, followed by calculation of crosslink densities (Figure 3), indicate a linear relation between crosslink density and DCP concentration. This is due to an increasing amount of free radicals when adding higher concentrations of peroxides which cause an efficient formation of intermolecular bridges. ${ }^{26}$ Even though these crosslink densities were determined in the EPDM bulk (cured at $180^{\circ} \mathrm{C}$ ), a similar linear increase can be expected near the interface, which is cured at lower temperatures. Therefore, the increased crosslink densities have to be taken into account if both chemical bonding and/or interdiffusion occurs because higher crosslink densities may limit interdiffusion due to restriction of chain mobility, while interfacial bonding may be promoted due to increased reactivity at the interface. ${ }^{4,11}$ 


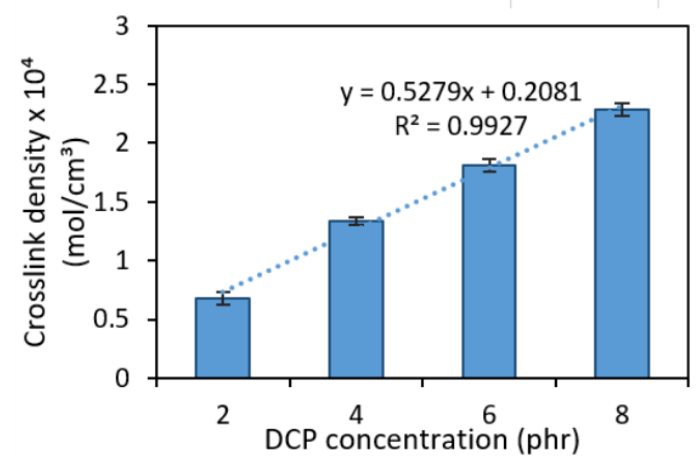

FIGURE 3 crosslink density, obtained from swelling measurements, in function of DCP concentration. The dotted line represent a linear fit, which is accompanied by the linear equation and the correlation coefficient $\mathrm{R}^{2}$. Error bars represent $95 \%$ confidence intervals.

\section{Physico-mechanical properties}

In Figure 4 mechanical properties are represented in function of DCP concentration. Adding higher concentrations of DCP clearly increases tensile strength and hardness (Figure $4 a, c$ ) respectively by $41 \%$ and $18 \%$, when going from $2 \mathrm{phr}$ to $8 \mathrm{phr}$ DCP. For compression set and elongation at break (Figure $4 b, d)$, an opposite trend was established with respective decreases of $77 \%$ and $50 \%$. These results confirm literature findings and can be ascribed to the general increase in crosslink density and dense network formation of carbon-carbon crosslinks. ${ }^{6,9}$ Thus, requirements in mechanical properties need to be taken into account when selecting the right peroxide concentration.

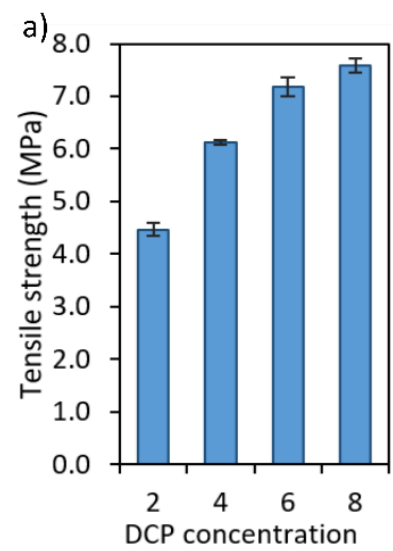

(phr)

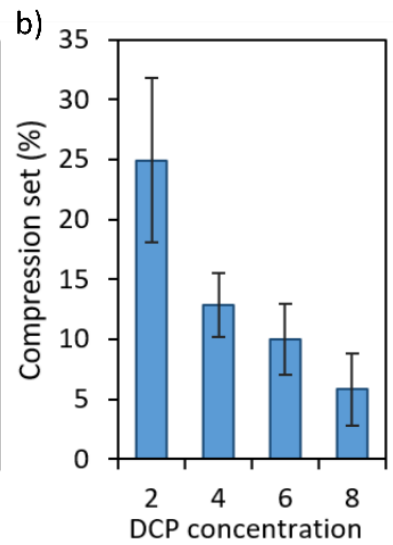

(phr)

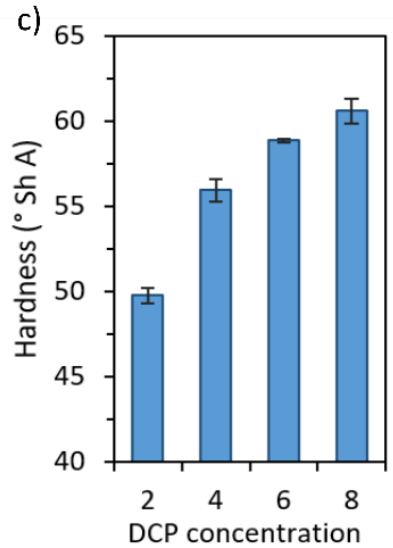

(phr)

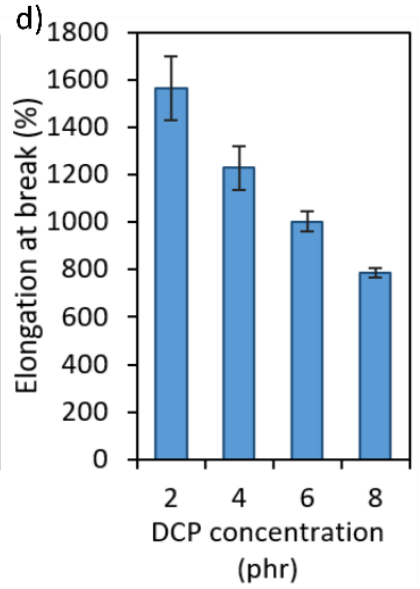

(phr)

FIGURE 4 Mechanical properties of EPDM in function of DCP concentration: tensile strength (a), compression set (b), Shore A hardness (c), and elongation at break (d). Error bars represent $95 \%$ confidence interval.

Heat aging was assessed by tensile and hardness measurements before and after exposure to $100^{\circ} \mathrm{C}$ during $72 \mathrm{~h}$. The effect of this thermo-oxidation process in relation to DCP concentration is important as thermal resistance is required for sealing applications at high temperature. Results are shown in Figure 5. Paired t-tests of tensile strengths did not show a significant difference between aged and unaged 
samples $(p<0.05)$ and the tensile strength was retained for all samples with at least $97 \%$. This high percentage of retention indicates good thermal stability. Thus, EPDM containing concentrations between 2 and 8 phr did not show any relative deteriorating in time in terms of tensile strength. However, hardness was significantly affected resulting in an average increase in hardness and $p$-value $<$ 0.050 ( 2 phr DCP: by $2.4^{\circ}$ Sh A, $p=0.000$; 4 phr DCP: by $1.3^{\circ}$ Sh A, $p=0.001 ; 6$ phr: by $1.3^{\circ}$ Sh $A, p=0.000 ; 8$ phr: by $\left.1.44^{\circ} \mathrm{Sh} A, p=0.001\right)$. This change in hardness may be due to additional crosslinking or hardening caused by side reactions. For 2 phr DCP, hardness increased most from unaged to aged samples. The unsaturations of EPDM are probably affected by oxidation due to the lower peroxide crosslinking efficiency at this low concentration, but overall the change in hardness remains limited. ${ }^{27,28}$
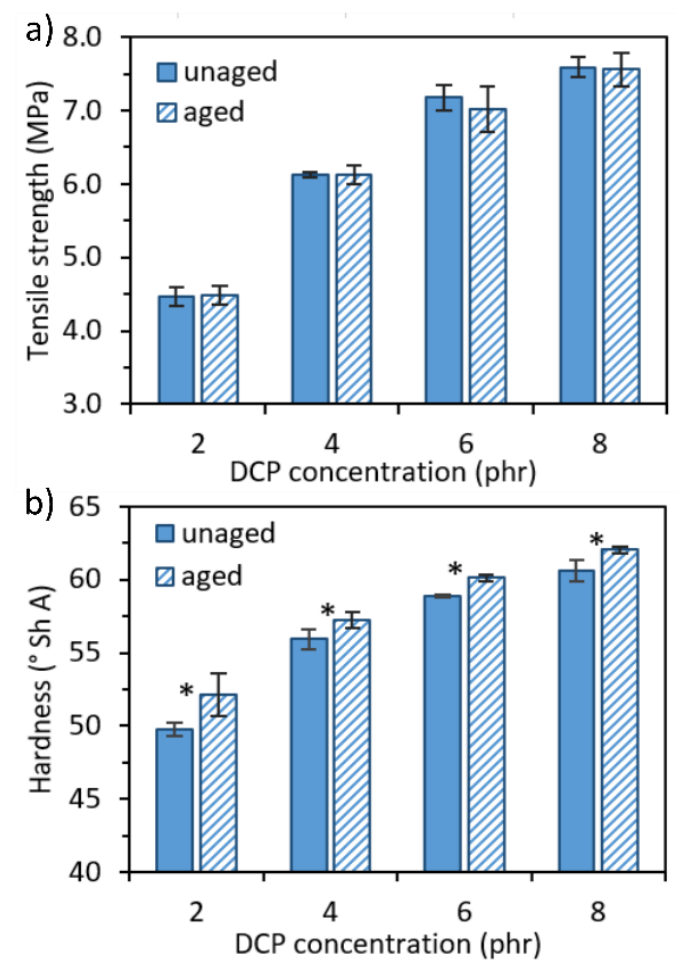

FIGURE 5 Tensile strength (a) and hardness (b) of unaged and aged samples. A significant difference $(p<0.05)$ between mean values of aged and unaged samples of each compound is indicated with *. Error bars represent $95 \%$ confidence intervals.

\section{Effect of Dicumylperoxide on the adhesion}

\section{EPDM-Thermoplastic compatibility}

In the previous study by the authors ${ }^{4}$, co-agents in the peroxide curing system significantly promoted wetting with the polar thermoplastic PC. Therefore, wetting behavior of molten PP, PE and PC was evaluated on EPDM substrates to analyze the influence of DCP concentration as well. Results of spreading of PE, PP and PC on each EPDM substrate (DCP2, DCP4, DCP6 and DCP8) are shown in Figure 6. Dynamic contact angles cannot be compared directly between the different thermoplastics (PP, PE 
and PC) as viscosity was not taken into account, but this was also not the goal of this study.
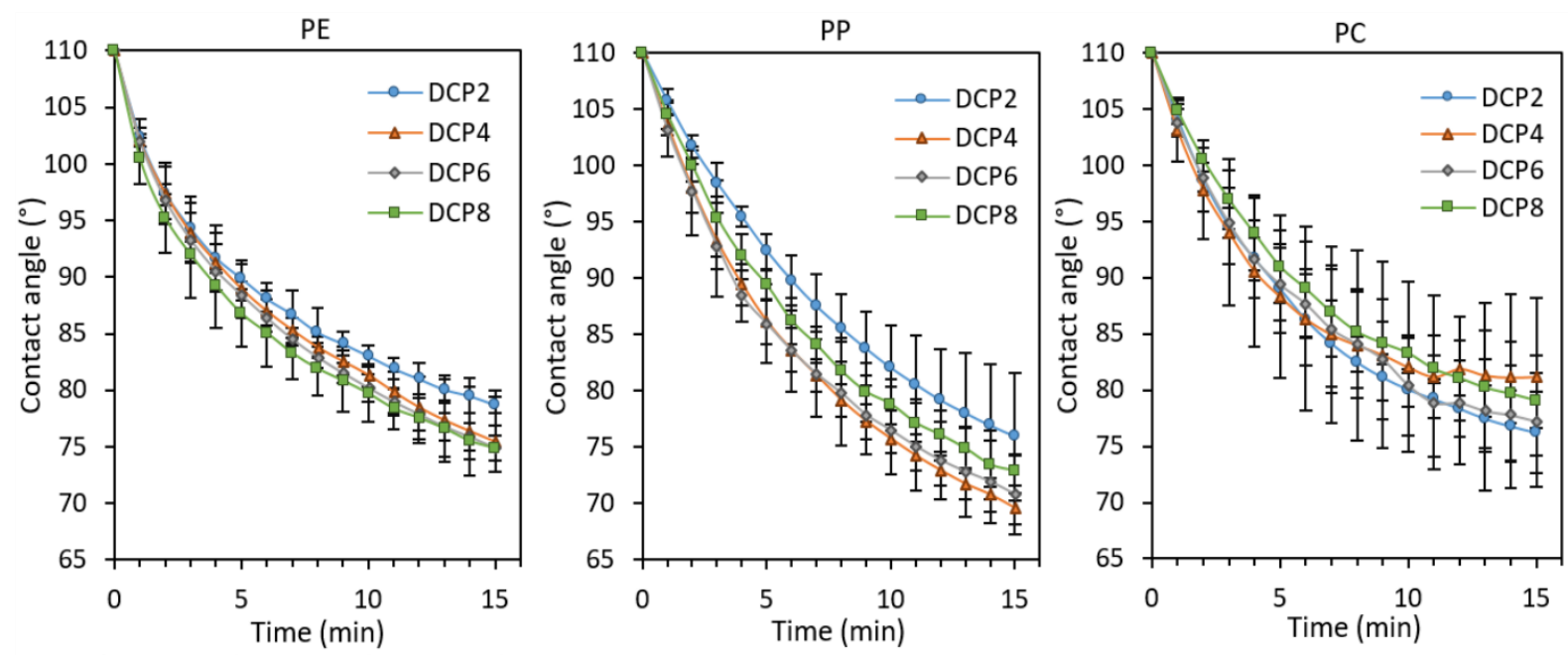

FIGURE 6 Contact angle measurements of thermoplastic melts of $\mathrm{PE}\left(180^{\circ} \mathrm{C}\right), \mathrm{PP}\left(200^{\circ} \mathrm{C}\right)$ and $\mathrm{PC}\left(230^{\circ} \mathrm{C}\right)$ during spreading on EPDM with 2 phr DCP (DCP2), 4 phr DCP (DCP4), 6 phr DCP (DCP6) and 8 phr DCP (DCP8). Error bars represent $95 \%$ confidence interval.

In Figure 6, contact angles of PP and PE on vulcanized substrates indicate better wetting, after $15 \mathrm{~min}$, on the substrates with 4, 6 and 8 phr DCP (respectively DCP4, DCP6 and DCP8) compared to 2 phr DCP (DCP2). The higher contact angles of DCP2 can be explained by ATR-FTIR measurements. In Figure 7, DCP2 shows a broad band for the hydroxyl group between 3100 and $3600 \mathrm{~cm}^{-1}$, which was not seen for DCP4, 6 or 8 . Thus, the surface of the DCP2 substrate indicates the presence of polar hydroxyl groups, possibly due to oxidation which will influence wetting on this substrate. Similarly, for PC better wetting was reached on DCP2, which can be ascribed to the polar groups on the surface. Overall, between 4, 6 and $8 \mathrm{phr}$, no significant difference was found on polar or non-polar thermoplastics when increasing the DCP concentration. Furthermore, measurements were executed on fully vulcanized substrates, where dicumylperoxide already participated in the vulcanization process leading to likely decomposition products methane, acetophenone and 2-phenylpropanol-2. ${ }^{5}$ However, neither dicumylperoxide, nor the decomposition products seem to significantly affect the surface composition of vulcanized EPDM with higher DCP concentrations which suggests that changes in polarity are limited. Thus, contrary to the previous study ${ }^{4}$ showing a significant influence of co-agent concentration on EPDM-thermoplastic compatibility, no compatibility differences in function of peroxide concentration were found. However, it might still be possible that shear induced enrichment of peroxides occurs at the interface during the injection molding process as proposed by Thust ${ }^{11}$. 
a)

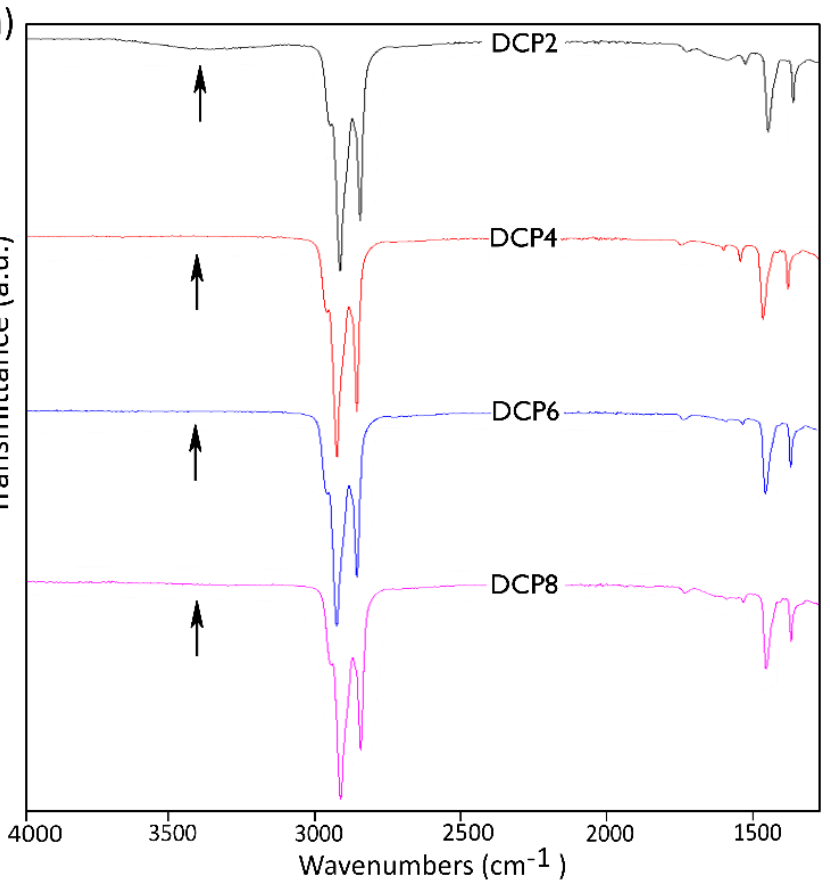

b)

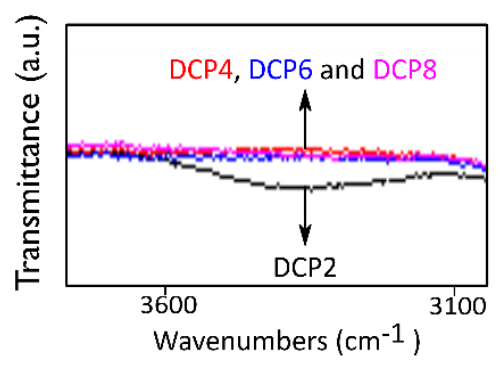

FIGURE 7 ATR-FTIR spectra of vulcanized DCP2 (2 phr DCP), DCP4 (4 phr DCP), DCP6 (6 phr DCP) and DCP8 (8 phr DCP) (a), and a magnification of the spectra between 3100 and $3600 \mathrm{~cm}^{-1}(\mathrm{~b})$.

\section{EPDM-thermoplastic co-vulcanization reactions}

The reaction mechanism during peroxide vulcanization of EPDM has already been extensively studied and reported. ${ }^{29-31}$ During exposure to heat, DCP will decompose in cumyloxy radicals which in turn can rearrange to yield methyl radicals that are less sterically hindered. ${ }^{5,6}$ These radicals can then abstract hydrogen atoms from secondary and mainly tertiary carbons on the EPDM main chain, and the allylic hydrogen in the ethylene-norbornene unit (ENB), resulting in respectively alkyl and allyl macroradicals. ${ }^{31}$ Orza ${ }^{31}$ provided a detailed description of peroxide crosslinking of EPDM with ENB as third monomer and based on this mechanism possible co-vulcanization reactions between EPDM and PE, PP or ABS are proposed in this study. For PC, crosslinking is unlikely due to the ester oxygen. Crosslinking unsaturated polymers, like PE and PP, can only occur through hydrogen abstraction, followed by a recombination of macro-radicals. ${ }^{5,6}$ However, main chain scission reactions are prone to occur in the presence of tertiary radicals, which are abundant in PP. In contrast, primary and secondary radicals are more susceptible towards combinations reactions, indicating possible successful crosslinking in PE. In ABS, styrene, butadiene, and acrylonitrile structural units are present, thus, both hydrogen abstracting reactions and addition reactions to the double bonds are possible. Specifically, for the double bonds, addition reactions are more amendable when they are located at the end of the polymer chain or in a side chain group, while in-chain double bonds are more sterically hindered. The presence of the electron withdrawing nitrile groups in $A B S$ reduces the reactivity of the in-chain double bond, prevailing abstraction reactions. ${ }^{5}$ In Figure 8, possible macro-radicals of EPDM, PE, PP and ABS are represented. The allyl and alkyl radicals in EPDM can form in a 1:1 ratio. ${ }^{5} \mathrm{PE}$ forms alkyl radicals on the $\mathrm{CH}_{2}$ positions and for PP the alkyl radical on the $\mathrm{CH}$ position was selected because it has the lowest bond 
strength (tertiary: $380 \mathrm{~kJ} / \mathrm{mol}$; secondary: $405 \mathrm{~kJ} / \mathrm{mol}$ ). ${ }^{5}$ Hydrogen abstraction reactions were presumed dominant in ABS forming stable benzyl and allyl macro-radicals due to possibility of resonance stabilization.

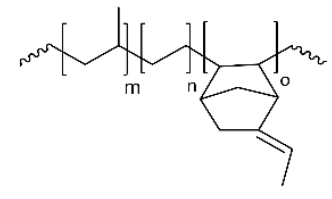

EPDM

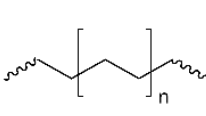

PE

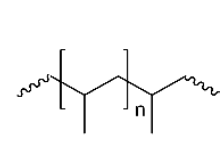

PP

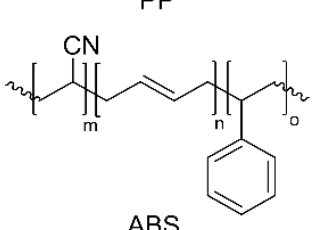

ABS

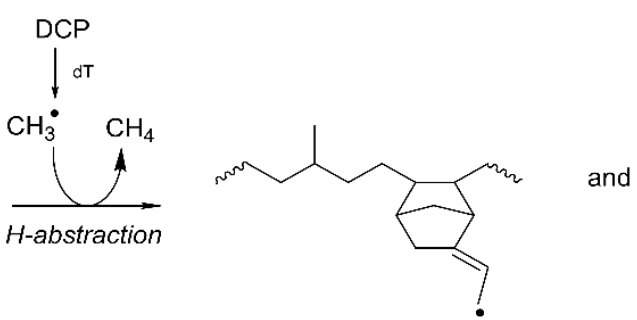

EPDM allyl macro-radical (EPDM॰)<smiles>CCCCCCCC</smiles>

PE alkyl macro-radical (PE॰)
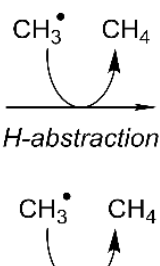

H-abstraction

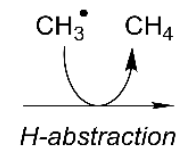

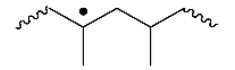

PP alkyl macro-radical (PP॰)

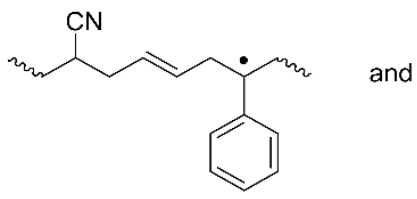

ABS benzyl macro-radical (ABS•)

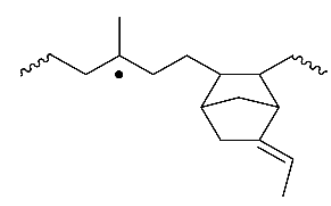

EPDM alkyl macro-radical (EPDM $\left.{ }^{\bullet}\right)$

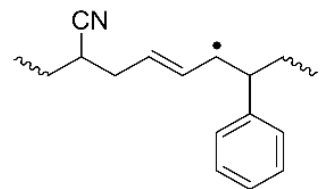

ABS allyl macro-radical (ABS*

FIGURE 8 Hydrogen abstraction from EPDM, PE, PP and ABS chain by cumyloxy radicals from DCP. The brackets indicate repeating units in each polymer, but these are removed in the reaction mechanism to give a clearer view.

In Figure 9 crosslinking reactions are represented that can occur between EPDM and PP, PE or ABS. Neither possible side reactions, nor the contribution of the co-agent are discussed. As Orza ${ }^{31}$ states, EPDM yields $\sim 25 \%$ alkyl/alkyl, $\sim 25 \%$ allyl/allyl and $\sim 50 \%$ allyl/alkyl combination crosslinks. Similarly, EPDM allyl and alkyl radicals might combine with an alkyl radical from PE resulting in allyl/alkyl and alkyl/alkyl crosslink, and through an addition to the double bonds of the ENB unsaturation an alkene/alkyl crosslink may occur. For PP, it has been suggested that between a PP radical and a neighbor chain with an allyl radical crosslinking is more probable. ${ }^{16}$ In this case, EPDM can provide the allyl radical making the allyl/alkyl crosslink most likely. However, it is important that both radicals are in close vicinity. ${ }^{16}$ Finally, several possible C-C bonds can form between ABS and EPDM as both polymers can donate hydrogens creating stable radicals. Besides combination reactions between ABS and EPDM radicals, addition reactions to the EPDM or ABS unsaturations, followed by $\mathrm{H}$-transfer might occur as well. For the addition reaction of the allyl EPDM or alkyl EPDM radical to ABS, an alkyl radical forms, due to the addition to the butadiene unsaturation. The most stable location was selected for this radical, i.e. reduced influence of electron withdrawing nitrile group. 
EPDM-PE crosslinks:

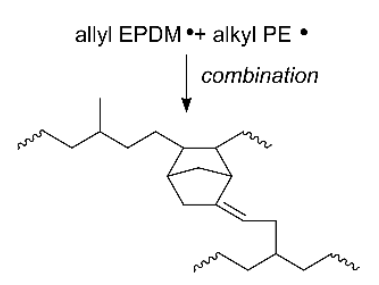

allyl/alkyl crosslink

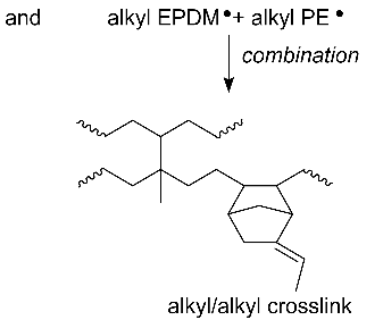

alkyl/alkyl crosslink and

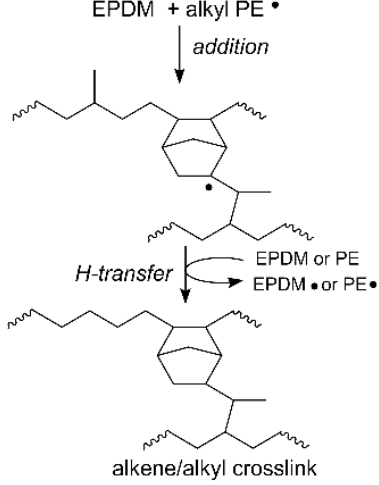

and

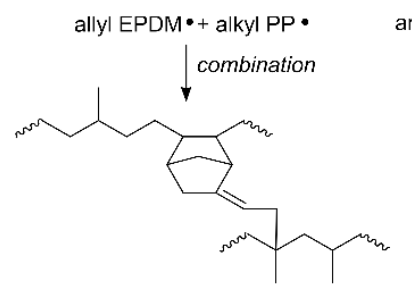

allyl/alkyl crosslink

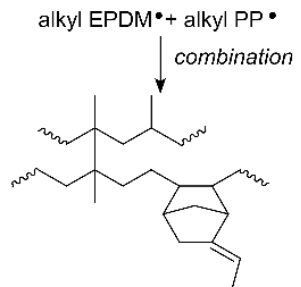

alkyl/alkyl crosslink
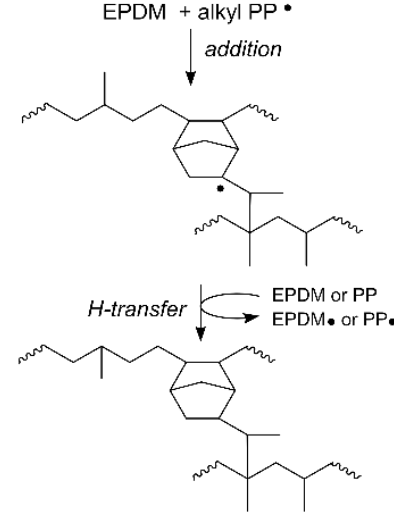

alkene/alkyl crosslink

EPDM-ABS $\underline{\text { crosslinks: }}$

alkyl EPDM • + benzyl ABS • and

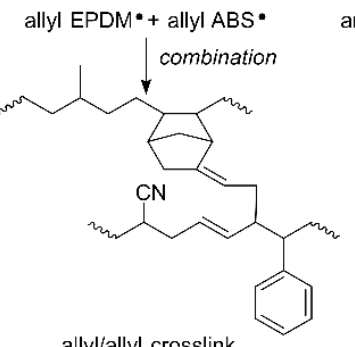

allyl/allyl crosslink

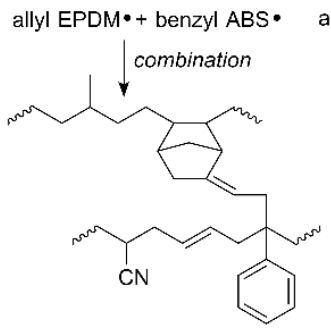

allyl/benzyl crosslink
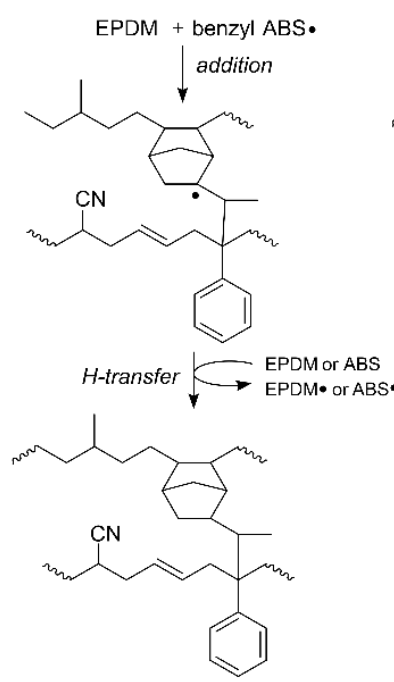

alkene/benzyl crosslink

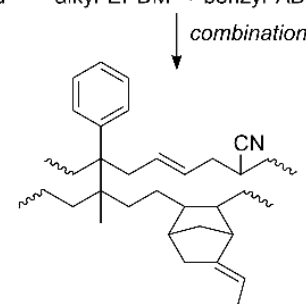

alkyl/benzyl crosslink
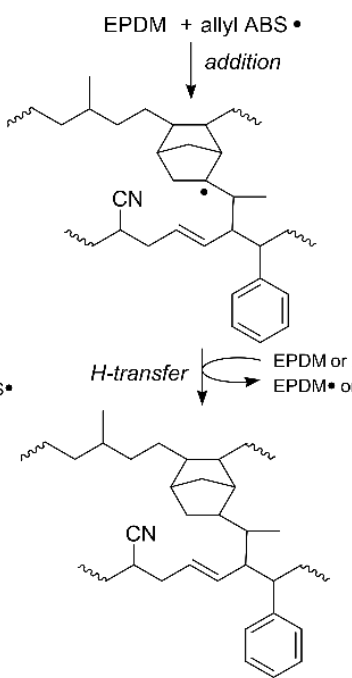

alkene/allyl crosslink

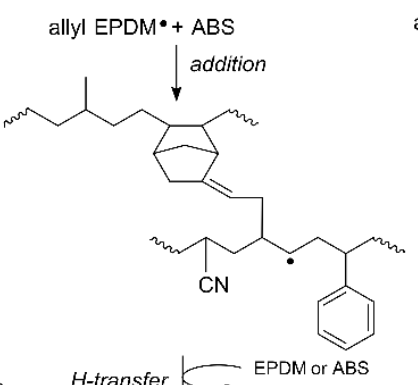

$H$-transfer $\longrightarrow$ EPDM or ABS

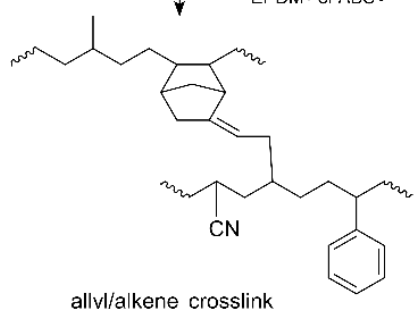

allyl/alkene crosslink

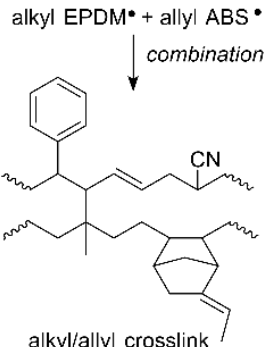

alkyl/allyl crosslink

alkyl EPDM • + ABS
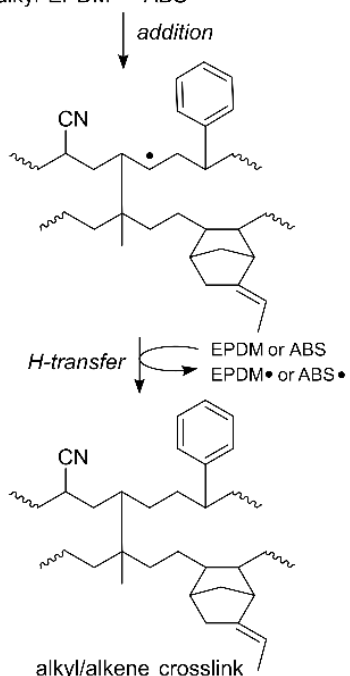
FIGURE 9 Co-vulcanization reactions between EPDM and PE, PP or ABS. For EPDM with PP or PE, two combination and one addition reaction result in three types of crosslinks. For EPDM with ABS four combination and four addition reactions result in a total of eight crosslink types.

\section{EPDM-Thermoplastic adhesion strength}

The adhesion strength between EPDM and PE, PP, ABS or PC was determined by tensile testing. Results are represented in Figure 10. Besides the adhesion strength for the different material combinations, total tensile strength $\left(\sigma_{t}\right)$ of the rubber bulk is shown as well per concentration.

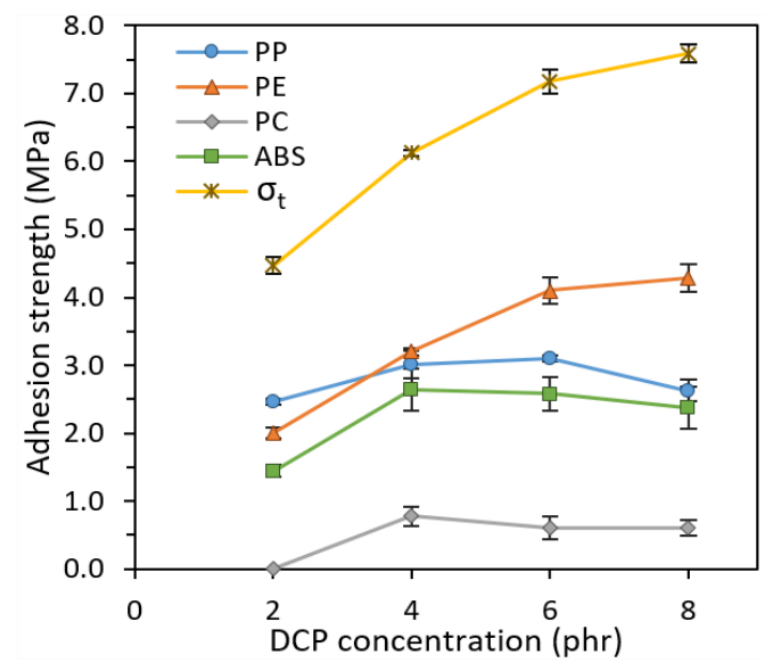

FIGURE 10 Adhesion strength in function of DCP concentration between EPDM and PE, PP, ABS and PC. Total tensile strength is represented as $\sigma_{t}$ as comparison. Error bars indicate $95 \%$ confidence intervals.

As seen in Figure 10, only the adhesion with PE increases continuously from 2 to 8 phr DCP. For PP, ABS and $P C$ the adhesion strength seems to improve up to a certain concentration but afterwards decreases again. Furthermore, the total tensile strength also increases with higher DCP concentrations. Thus, to analyze whether the adhesion strength does not merely improve due to the increased EPDM strength, values of adhesion strength were compared to the total tensile strength of EPDM at each concentration by calculating an adhesion percentage (eq.(5)) which is represented in Figure 11. An adhesion percentage of $100 \%$ is unlikely due to the different vulcanization temperatures in the bulk and at the interface. Consequently, crosslink densities will be higher in the bulk than near the interface due to the higher curing temperature, causing a higher tensile strength. In addition, the combination of hard-soft material causes a mismatch in Poisson ratio and stiffness leading to debonding near the edges. ${ }^{1 .}$ Thus, fracture mainly occurs near the edges cohesively or adhesively. 


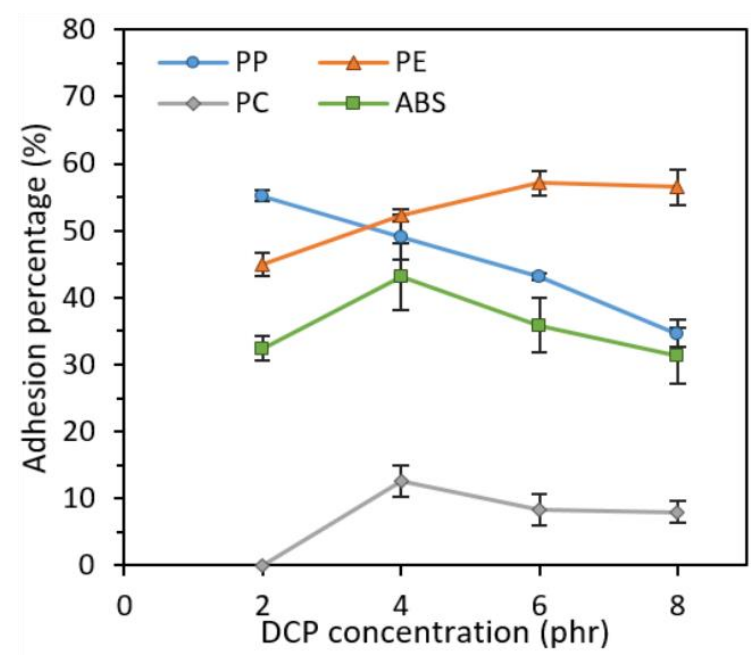

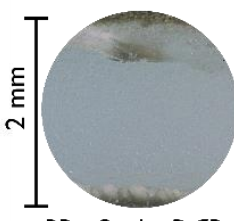

PP - 2 phr DCP

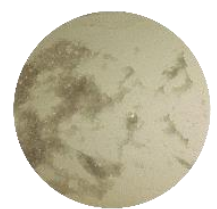

$A B S-4$ phr DCP

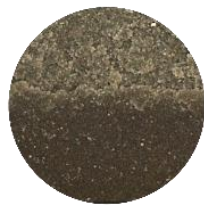

PE - 6 phr DCP

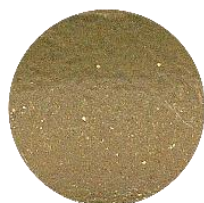

PC - 4 phr DCP

FIGURE 11 Adhesion percentage (adhesion strength divided by total strength) in function of DCP concentration for PP, PE, PC and ABS. The error bars represent $95 \%$ confidence intervals. The microscopic images show a circular zone ( $2 \mathrm{~mm}$ radius) of the fracture surfaces at the thermoplastic side. Black indicates the rubber and white the thermoplastic. For PC - 4 phr DCP, no rubber is visible and for PE - 6 phr DCP only rubber is visible.

At the interface between EPDM and thermoplastics, adhesion mechanisms like chemical bonding or interdiffusion are expected. During injection molding, the crosslinking reaction in the EPDM part may influence these adhesion mechanisms at the interface. Specifically, when interdiffusion is dominant, formation of crosslinks will limit chain mobility. However, the radicals created during curing can increase reactivity near the interface and improve co-vulcanization which entails chemical bonding. ${ }^{4}$ When both adhesion mechanisms are plausible, a combination of both is expected as also stated by Thust ${ }^{11}$.

In case of PP, scission reactions compete with crosslinking. Results of adhesion percentage indicate that increasing the DCP concentration drastically decreases the adhesion percentage (from $55 \%$ at 2 phr to $35 \%$ at $8 \mathrm{phr})$ in a linear manner $\left(\mathrm{R}^{2}=0.9921\right)$. At the interface, both chemical bonding and interdiffusion could occur as adhesion mechanism, but it seems that both mechanisms are adversely affected by higher DCP concentrations. Interdiffusion is limited due to higher crosslink density in EPDM at the interface and probably degradation of PP prevails over crosslinking. This negative effect of higher peroxide concentrations was also seen in studies of EPDM/PP TPVs. ${ }^{71}$ In addition, as peroxide concentration increases, more scission may occur which reduces molecular weight of polypropylene near the interface, therefore, the adhesion caused by interdiffusion may be limited due to a lack of entanglements. ${ }^{32}$ Thus, for EPDM-PP a low DCP concentration is recommended in combination with a higher co-agents concentration, as a previous study by the authors showed that 6 phr TMPT could reduce PP degradation at $3.2 \mathrm{phr}$ DCP.

The adhesion percentage between EPDM and PE gradually increases with higher peroxide concentration (by $12 \%$ from 2 to $6 \mathrm{phr}$ ) up to a maximum at $6 \mathrm{phr}$ DCP with a cohesive failure. At higher concentrations, i.e. $8 \mathrm{phr} \mathrm{DCP}$, adhesion is not further improved, but merely adhesion strength increases due to an increase in rubber strength (Figure 10). Literature also indicates the successful crosslinking of $\mathrm{PE}$ by DCP and confirms that increasing concentrations can lead to higher crosslink density of PE. ${ }^{14,33}$ 
However, Cespedes et al. ${ }^{14}$ highlighted that improved properties are only reached up to certain DCP concentration in TPVs containing EPDM, HDPE and ground tire rubber because the thermoplastic phase may be affected by a thermo-oxidation (degradation) process. Thus, similarly in this study EPDM-PE adhesion improves up to $6 \mathrm{phr}$ DCP, which can be mainly attributed to an increase in chemical bonding or formation of more C-C bonds between EPDM and PE. Chemical bonding dominates over interdiffusion because the higher crosslink density would normally limit chain mobility. Additionally, to improve the adhesion even more, co-agent triallyl cyanurate (TAC) would be recommended as Laing et al. ${ }^{4}$ indicated better adhesion at $1.5 \mathrm{phr}$ TAC with $3.2 \mathrm{phr}$ DCP, while TMPT did not enhance adhesion.

The adhesion of $A B S$ is only improved up to 4 phr DCP after which the adhesion percentage decreases again. PC shows a similar trend. In case of ABS, crosslinks between EPDM and ABS chains are possible. However, degradation may occur as well. Therefore, crosslinking reactions may be promoted up to 4 phr, but higher concentration may limit interdiffusion and cause chain scission of ABS near the interface instead of promoting crosslinking. At $4 \mathrm{phr}$, the ABS surface showed occasional partial cohesive failure. For PC, no adhesion was reached with EPDM containing 2 phr DCP during injection molding. In contrast, contact angle measurements indicated better wetting on 2 phr DCP, but FTIR measurements showed the presence of polar groups due to degradation. In unvulcanized EPDM with 2 phr DCP, these polar groups were not present yet at the interface and therefore did not affect adhesion during injection molding. Probably, this low concentration did not suffice to induce an adhesion through interdiffusion, but at higher DCP concentrations, a low adhesion was possible. Similarly as for ABS, 4 phr DCP is most optimal for adhesion with $\mathrm{PC}$, but $\mathrm{ABS}$ reaches a higher adhesion percentage of $43 \%$ compared to $13 \%$ for $\mathrm{PC}$ as crosslinking may occur at the EPDM-ABS interface. Higher concentrations do not further improve adhesion with PC. This is in agreement with wetting measurements as compatibility was not affected by higher peroxide concentrations. The interdiffusion process will, however, be limited by higher crosslink density in EPDM causing a decrease in adhesion percentage. For polar thermoplastics, it would be recommended to implement a high TAC concentration to further improve adhesion as was shown in the previous study by the authors. ${ }^{4}$

\section{CONCLUSIONS}

In this study, the influence of DCP in EPDM on the adhesion with polar and non-polar thermoplastics was investigated. Results of contact angle measurements showed that compatibility with polar or nonpolar thermoplastics did not change with higher DCP concentrations. However, adding higher concentrations of the peroxide curing agent significantly affected the adhesion percentage between EPDM and PE, PP, ABS or PC. Consequently, changes in adhesion percentage can be mainly attributed to changes in adhesion mechanisms occurring after contact between both polymers. Furthermore, the adhesion percentage results confirm the occurrence of chemical bonds between EPDM and PP, PE or ABS. The optimal DCP concentration also appeared to be EPDM-thermoplastic specific:

- For PE, higher DCP concentration improved the adhesion percentage up to $57 \%$ at $6 \mathrm{phr}$ showing a full cohesive failure. At this concentration, co-vulcanization between EPDM and PE may be promoted.

- $\quad$ PP tends to degrade when adding higher DCP concentrations causing a linear decrease in adhesion percentage from $55 \%$ at 2 phr to $35 \%$ at 8 phr. Therefore, a low DCP concentration is 
recommended with the addition of higher co-agent concentration to boost crosslinking which may also limit EPDM bulk degradation.

- For the polar ABS and PC, 4 phr DCP caused respectively adhesion percentages of $43 \%$ and $13 \%$. In case of EPDM with ABS, a combination of crosslinking and interdiffusion is expected leading to higher adhesion strength percentages than for EPDM with PC were interdiffusion is deemed dominant.

Depending on the material combination, influences of the recommended DCP concentration on EPDM bulk properties need to be taken into account because higher concentrations signify higher tensile strength and hardness, as well as lower compression set and elongation at break. Only at $2 \mathrm{phr}$, heat aging occurs, but for EPDM-PP the suggested higher co-agent concentration could prevent side reactions. Furthermore, to validate the current findings, a more direct characterization of the adhesion mechanism is deemed necessary, e.g. by applying Raman spectroscopy and Scanning Electron Microscopy with Energy Dispersive Spectroscopy (SEM-EDS).

\section{ACKNOWLEDGEMENTS}

B. Laing acknowledges Research Foundation - Flanders (FWO) for funding this PhD Fellowship strategic basic research (1SB0319N). The authors also acknowledge the company Hercorub NV, Belgium for mixing and providing the uncured rubber material. Furthermore, thanks are due to prof. Leen Thomassen for her suggestions concerning the EPDM-thermoplastic co-vulcanization reactions and to Datwyler Pharma Packaging Belgium NV for providing the moving die rheometer.

\section{REFERENCES AND NOTES}

1. Bex, G. J. Ph.D. Thesis, KU Leuven, Diepenbeek, 2019.

2. Bex, G. J.; Desplentere, F.; De Keyzer, J.; Van Bael, A. Int. J. Adv. Manuf. Technol. 2017, 92, 25992607.

3. Bex, G. J.; Six, W.; Laing, B.; De Keyzer, J.; Desplentere, F.; Van Bael, A. J. Appl. Polym. Sci. 2018, . $135,46495$.

4. $\quad$ Laing, B.; De Keyzer, J.; Seveno, D.; Van Bael, A. J. Appl. Polym. Sci. 2019, 48414.

5. $\quad$ Kruželák, J., Sýkora, R., and Hudec, I. Rubber Chem. Technol. 2017, 90, 60-88.

6. Dluzneski, P. R. Rubber Chem. Technol. 2001, 74, 451-492.

7. Babu, R.R., Singha, N. K., and Naskar, K. Express Polym. Lett. 2008, 2, 226-236.

8. Saleesung, T.; Saeoui, P.; Sirisinha, C.J. Appl. Polym. Sci. 2017, 134, 44523.

9. Nah, C., Kim, S., Shibulal, G., Yoo, Y., Mensah, B., Jeong, B., Hong, B., and Ahn, J. Int. J. Hydrogen Energy 2015, 40, 10627-10635.

10. Wang, H.; Zhao, S.; Wrana, C. J. Macromol. Sci. B. 2017, 56, 39-52.

11. Thust, T. Ph.D. Thesis, Martin-Luther-Universität, Halle-Wittenberg, 2014.

12. Anbarasan, R.; Babot, O.; Maillard, B. J. Appl. Polym. Sci. 2004, 93, 75-81.

13. Kim, K. J.; Ok, Y. S.; Kim, B. K. Eur. Polym. J. 1992, 28, 1487-1491.

14. Céspedes, R. , Gámez, J., Velázquez, M., Belmontes, F., De Leõn, R., Fernández, O., Orta, C., and Hernández, E. J. Appl. Polym. Sci. 2014, 131, 39901.

15. Naskar, K., Noordermeer, J. W. M. J. Elastomers Plast. 2006, 38, 163-180.

16. Arnold, M.; Borsig, E.; Ra, M.; Bucka, H.; Reichelt, N. Prog. Polym Sci. 2002, 27, 1195-1282.

17. Vennemann, N., Bökamp, K., and Bröker, D. Macromol. Symp. 2006, 245-246, 641-650 
18. Zaimova, D., Bayraktar, E., and Dishovsky, N. J. Achiev. Mater. Manuf. Eng. 2011, 44, 161-167.

19. J Brandrup, J. Polymer handbook, 4th ed.; Wiley: New York, 1999.

20. Bex, G.J., Seveno, D., De Keyzer, J., Desplentere, F., and Van Bael, A. J. Appl. Polym. Sci. 2017, 135, 46046.

21. Haberstroh, E., Ronnewinkel, C. J. Polym. Eng. 2001, 21, 303-318.

22. Kisslinger, T., Bruckmoser, K., Lucyshyn, T., Langecker, G. R., Resch, K., and Holzer, C. AIP Conf. Proc., 2014, 1593, 170-174

23. Awaja, F., Gilbert, M., Kelly, G., Fox, B., and Pigram, P. J. Prog. Polym. Sci., 2009, 34, 948-968.

24. Kruželák, J., Sýkora, R., and Hudec, I. Chem. Pap. 2016, 70, 12, 1533-1555.

25. Saleesung, T.; Reichert, D.; Saalwächter, K.; Sirisinha, C. Polymer (Guildf)., 2015, 56, 309-317.

26. Kruželák, J., Sýkora, R. and Hudec, I. J. Polym. Eng. 2014, 34, 617-624.

27. Kruželák, J., Sýkora, R. and Hudec, I J. Polym. Res. 2015, 22, 1-9.

28. Nabil, H.; Ismail, H.; Azura, A. R. J. Vinyl Addit. Technol. 2014, 20, 99-107.

29. Orza, R. A.; Magusin, P. C. M. M ; Litvinov, V. M.; Van Duin, M.; Michel, M. A. J. Macromolecules, 2009, 42, 8914-8924.

30. Van Duin, M.; Orza, R.; Peters, R.; Chechik, V.Macromol. Symp., 2010, 291-292, 66-74.

31. Orza, R. Ph.D. Thesis. Eindhoven University of Technology, Eindhoven, 2008.

32. Yokomizo, K.; Banno, Y.; Yoshikawa, T.; Kotaki, M. Polym. Eng. Sci., 2013, 53, 2336-2344.

33. Liu, S. Q., Gong, W. G., and Zheng, B. C. J. Macromol. Sci. Part B Phys. 2014; 53, 67-77. 